\title{
How social learning influences further collaboration: experiences from an international collaborative water project
}

\author{
$\underline{\text { Joanne Vinke-de Kruijf }}^{1}$, $\underline{\text { Hans Bressers }}^{2}$ and Denie C. M. Augustijn ${ }^{3}$
}

\begin{abstract}
Social learning in collaborative settings can play an important role in reducing water management problems. In this paper we analyze the nature and effects of these learning processes in an international collaborative setting. We assert that social interactions contribute to substantive and relational learning, which involves changes in the motivations, cognitions and resources of individual actors. In addition, interactions may contribute to social learning, which is the case when actors develop collective outcomes on which further collaboration can be based. We use these theoretical insights to examine a water project in which Dutch and Romanian actors collaborate. Their interactions changed their individual motivations, cognitions, and resources and led to collective outcomes. Some of the learning processes were constructive, others were not. Because the unconstructive learning by external actors was decisive, the collaboration did not establish a basis for further collaboration. The case study demonstrates that a single project can include multiple and diverse social learning processes, which may have a positive or negative effect on further collaboration. Whose learning has most impact closely relates to how resources are distributed across actors, and hence the context of a learning process. Thus, whether learning forms a basis for further collaboration depends not only on 'how much' actors learn but in particular on 'who learns what.'
\end{abstract}

Key Words: international collaboration; Romania; social learning; water resource management

\section{INTRODUCTION}

Water resources management affects a wide variety of uses and users with diverse perspectives and involves high levels of uncertainty. As a result, water problems are often complex and unstructured (Hommes et al. 2009, Huitema et al. 2010). Learning through social interaction is widely seen as an important means of coping with such problems (Schusler et al. 2003, Pahl-Wostl et al. 2007, Steyaert and Jiggins 2007, Muro and Jeffrey 2008, Huitema et al. 2010, Gerlak and Heikkila 2011). In natural resource management literature, social learning is often used in relation to adaptive management, collaborative management, and more recently to adaptive comanagement. In this paper, we focus on the social learning that occurs in collaborative, multiactor settings through processes of knowledge sharing, deliberation, and interaction, which may establish a basis for collective action (Cundill and Rodela 2012). We define social learning as a process that occurs through social interaction and leads to changes in understanding that go beyond the individual level (Reed et al. 2010).

The focus of this paper is on a particular collaborative setting, namely an international knowledge transfer project in which multiple actors from different countries engage in an interactive process for the purpose of reducing a water management problem. The objective of such an international project is similar to the objective of many multiactor river basin management processes. An important difference is, however, that actors involved in an international knowledge transfer project do not necessarily share or depend on the same water catchment (Ison et al. 2007, PahlWostl et al. 2007, Tàbara and Pahl-Wostl 2007). Nevertheless, actors involved are to some extent mutually dependent on the resources of one another in as far as they are complementary and needed to achieve a common goal. In projects, such as this case, actors of the transferring country contribute finances and relevant knowledge, but are not in the position to implement measures and have no context-specific knowledge. Actors of the receiving country can make use of these external resources to reduce environmental problems, which are difficult to reduce otherwise (Vinke-de Kruijf et al. 2012). Because international projects tend to involve a rather heterogeneous group of actors, they provide many opportunities and also obstacles for learning. When actors have more diverse professional, organizational, and sociocultural backgrounds, they tend to have more difficulties in understanding each other, and thus in learning from and about each other (Stenmark 2002). Nevertheless, when actors have diverse backgrounds, interactions may contribute to the development of more overlapping views, mutual trust, and a willingness to collaborate more closely (Rist et al. 2006).

This paper contributes to the empirical research on social learning. We particularly address research gaps concerning the relation between, on the one hand, interactive processes and social learning and, on the other hand, the development of a shared understanding between relevant actors on which agreement and collective action can be based (Muro and Jeffrey 2008, Cundill and Rodela 2012). The central questions of this paper are: What are the nature and effects of social learning? To what extent does social learning contribute to further collaboration in international collaborative settings? To answer these research questions, we build upon the scholarly literature on social learning and policy implementation and the experiences of an international water project.

\section{LEARNING IN COLLABORATIVE SETTINGS}

In this paper, we focus on social learning that occurs in international collaborative processes. Within this context, we consider learning to be "real" social learning when the following three conditions are met: (1) learning has occurred through social 
interactions; (2) the interactions have led to changes at the individual level; and (3) the interactions have led to changes that go beyond the individual level (Reed et al. 2010).

Social learning can be facilitated by creating interactive settings in which actors can share and reflect upon different perspectives, experiences, and types of knowledge (Schusler et al. 2003, Koppenjan and Klijn 2004, Rist et al. 2006, Hommes et al. 2009). These interactions may lead to an increase of knowledge and insights as well as the growing capacity to make use of knowledge, experience, and understanding (Bierly et al. 2000, Leeuwis and Van den Ban 2004). Growing capacity refers here to an increase of skills or qualities (Pahl-Wostl et al. 2007, Muro and Jeffrey 2008). The increase of knowledge, insights, or skills may remain at the individual level but may also extend to the collective level (De Laat and Simons 2002, Newig et al. 2010, Gerlak and Heikkila 2011). For example, learning may lead to shared ideas, rules, and policies (Newig et al. 2010, Gerlak and Heikkila 2011). Next to "social outcomes," social learning may promote the realization of environmental outcomes, such as, flood risk reduction or improved water quality (Koontz and Thomas 2006, Mandarano 2008). Thus, interactions may lead to individual and collective outcomes, such as, the acquisition of knowledge and skills, changes in attitudes and cognitions, relations, trust, common understanding mutual agreement, and collective action (Muro and Jeffrey 2008).

The increase of knowledge and insights, i.e., learning, may concern substantive aspects and also relational including institutional aspects (Schusler et al. 2003, Koppenjan and Klijn 2004, Pahl-Wostl et al. 2007, Huitema et al. 2010). Substantive learning involves the acquisition of factual knowledge that leads to an increase of knowledge and insights about the problem and its solutions (Koppenjan and Klijn 2004, Huitema et al. 2010) as well as the acquisition of technical skills or qualities (Pahl-Wostl et al. 2007, Muro and Jeffrey 2008). Relational learning involves an increase of knowledge and insights in the role of other actors and mutual dependencies as well as the ability of actors to develop relations, mutual trust, and shared meanings that potentially support their interaction (Koppenjan and Klijn 2004). Relational learning includes the development of relational qualities (PahlWostl et al. 2007), enhanced trust, and improved understanding of other actors' perspectives (Huitema et al. 2010).

For our study, we connect the presented insights about social learning with an actor-centered theory of policy implementation: the Contextual Interaction Theory. The main starting-point of this theory is that interactive processes are shaped by the key characteristics of the actors involved. Actors are defined here as individual persons, e.g., an expert or a civil servant, who act as representatives of an organization or collective entity (Newig et al. 2010). The key characteristics of actors are their motivations, cognitions, and resources.

- Actors' motivations drive their actions and are reflected in their willingness to participate in a collaborative process. They are rooted in personal and organizational goals and values and influenced by external pressures, e.g., social, political, or economic, and self-effectiveness assessment. The concept of self-effectiveness assessment is based on the recognition that competent functioning requires skills as well as the belief that one is capable of using these skills to accomplish a certain performance (Bandura 1986).

- Cognitions refer to the information an actor holds to be true. They are rooted in an actor's interpretation of reality, which is influenced by frames of reference and observations of reality. Cognitions are reflected in an actor's formulation of the problem, e.g., the nature, meaning, and urgency of the problem at stake and its potential solutions, and the process, e.g., the relevance and potential of the adopted or proposed approach.

- Resources refer to the capacity of an actor to act and are, in a relational setting, also sources of power. It includes human resources (skilled people), knowledge resources (information, data, and knowledge), financial resources, and institutional resources (formal and informal capacity and power to get things done; Owens 2008, Vinke-de Kruijf 2011).

There are mutual relations between an interaction process and actor characteristics: the characteristics shape the process and are also shaped by the process. In addition, there are mutual relations between the actor characteristics themselves: every change in one of the characteristics influences the other two. Thus, when an actor's cognition changes as a result of learning, the motivation and resources of that actor can also change. Obviously, other (contextual) factors, such as the governance structure in place, may influence interaction processes, but they only do so via the characteristics of actors involved (Bressers 2009, De Boer and Bressers 2011).

Learning involves changes in actor characteristics. These changes may remain at the individual level, i.e., only change the motivations, cognitions, and resources of individual actors. In addition, interactions can enable changes that go beyond the individual level, including the development of a consistent set of values, common reference frames, and pooling of resources (Bressers 2009). In terms of the three actor characteristics, constructive interactions may lead to the development of a joint motivating goal, the creation of a "negotiated knowledge" base and the mobilization of necessary resources, by pooling them, if necessary (Vinke-de Kruijf et al. 2012). "Negotiated knowledge" means here that actors have developed similar cognitions concerning the significance, meaning, and (scientific) validity of knowledge (Koppenjan and Klijn 2004, Hommes et al. 2009).

In addition to the mentioned collective outcomes, actors may develop trust (Bressers 2009). Trust can be defined as an actor's "intention to accept vulnerability based upon positive expectations of the intentions or behavior of another" (Rousseau et al. 1998:395). Trust becomes relevant when an actor needs to take risks and depends on other actors. In relatively new relations, the willingness of actors to trust is generally limited, since trust is based only on information that is, for example, provided by others or by certification. When actors interact with each other over a longer period of time, they gain additional information about other actors that is rooted in relational experiences. Positive relational experiences increase an actors' willingness to trust another actor. Negative experiences have the opposite effect (Rousseau et al. 1998). Mutual trust can be a strong motivational 
Fig. 1. Conceptual model of the relation between learning and actor characteristics in actor-interaction processes.

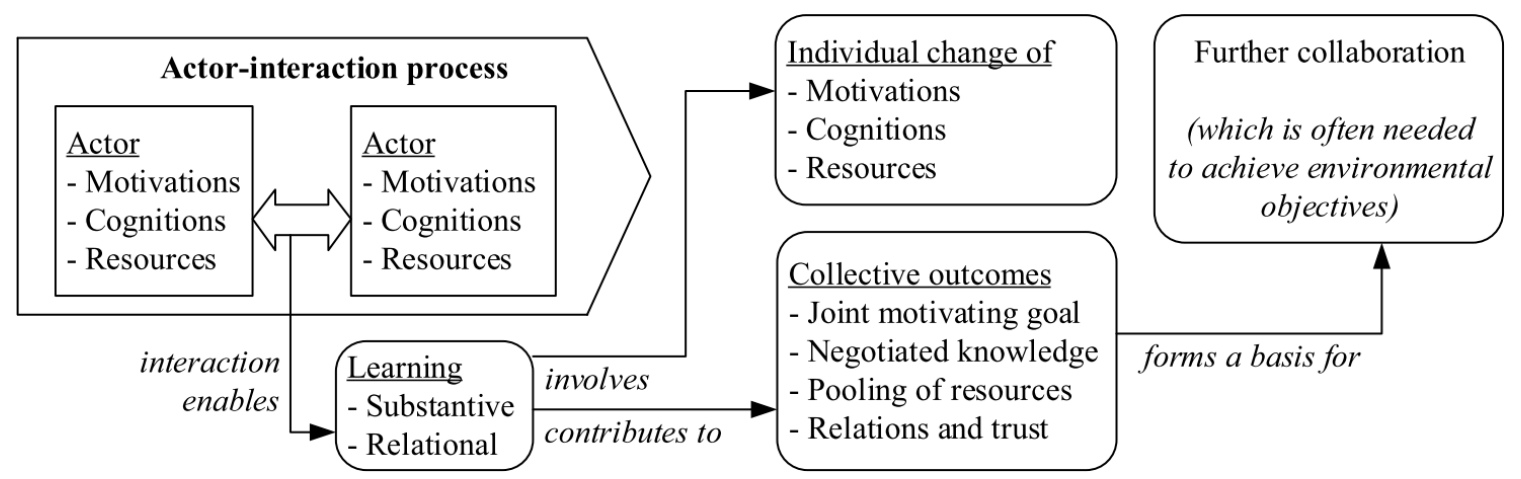

factor and accelerate collaboration processes (De Boer and Bressers 2011). Positive relational experiences forming a basis for trust are thus another collective outcome of interaction processes.

Figure 1 integrates the presented ideas about learning into a conceptual model. The figure shows that interactions enable substantive learning and relational learning. Learning changes the characteristics of individual actors. In addition, it may contribute to the development of collective outcomes. These collective outcomes provide a basis for further collaboration, which are often needed to actually achieve environmental objectives. In our conceptualization of learning and social learning, the term "social learning" is reserved for learning that involves both changes at the individual level and at the collective level.

\section{CASE STUDY PROJECT AND METHODS}

\section{Case study: an international water project}

To better understand the nature and effects of learning in international collaborative settings, we examined the project "Integrated Water Management for the Tecucel River Basin." The Tecucel is a small river (length of $\sim 25 \mathrm{~km}$ ) in the Romanian PrutBarlad basin, which is a sub-basin of the Danube river basin. In September 2007, a flash flood on this river caused three deaths and economic damage of $\sim 6$ million Euros in the city of Tecuci and several neighboring communities (Zaharia et al. 2008). The flood also had a major impact on drinking water supply and wastewater treatment. Recognizing that these different water management aspects are often, at least partly, interconnected, the project aimed to develop a master plan that would pay attention to flooding, drinking water, and wastewater. The project was implemented through collaboration between Dutch and Romanian actors between September 2009 and June 2011.

A master plan that takes into account flooding, drinking water, and wastewater is rather uncommon in Romania because they are seen as separate tasks. For water resources management (quality and quantity), the Ministry of Environment and Forests has under its authority the National Administration for "Romanian Waters." This administration operates through 11 regional water branches, one for every main sub-basin of the country (Vinke-de Kruijf et al. 2013a). At the time of project implementation, all branches of Romanian Waters were preparing master plans for flood risk management within the context of the European Floods Directive (2007/60/EC). The master plan for the affected area (finalized in 2009) also included measures for the reduction of flood risks along the Tecucel River. However, in 2011 the Ministry decided that the implementation of these measures did not have priority.

The delivery of drinking water and the transportation and treatment of wastewater are also coordinated by the Ministry of Environment and Forests. At the time of project implementation, operational tasks were being shifted from the local level to the regional level (Vinke-de Kruijf et al. 2013a). At the beginning of the project, the local administration of Tecuci was still responsible for drinking water and wastewater in this city. This changed in October 2010, when the water company of Tecuci was integrated into the regional company Apa-Canal Galaţi. In the process of becoming a regional operator, Apa-Canal had prepared a master plan to bring services in line with the European Directives on drinking water (98/83/EC) and wastewater (91/271/EEC). This master plan includes measures in the city of Tecuci.

The initiative for the collaborative project came from the Dutch regional water authority Hunze \& Aa's. The authority heard from a Romanian intern about the flood when it had just finished another project with the responsible branch of Romanian Waters. Discussions between both water authorities and an exploratory visit resulted in a project idea and the formation of two project teams and two advisory committees. The Dutch team consisted of six organizations from the north of the Netherlands: a water authority (initiator), the municipality of Groningen, water company Groningen, the Dutch Governmental Service for Land and Water Management (DLG, project management), a consultancy company, and a production company, which produces, among other things, units for wastewater treatment. On the Romanian side, an integrated team was formed with representatives of local public authorities (the City of Tecuci and two neighboring communities), the water company of Tecuci, and a local office of the Romanian Waters branch. The team was chaired by a civil servant of Tecuci and supported by a project secretary (a former intern of the Dutch water authority, employed at a municipality that was not involved) and a technical assistant 
Fig. 2. Project structure: a Dutch steering group and team and a Romanian consultative committee and team.

\begin{tabular}{|l|l|}
$\begin{array}{l}\text { Dutch Steering Group: } \\
\text { High level representatives of all Dutch } \\
\text { organizations involved }\end{array}$ \\
$\begin{array}{l}\text { Dutch team with experts of: } \\
\text { - Regional water board } \\
- \text { Government agency (DLG) }\end{array}$
\end{tabular}

(an employee of a Romanian consultancy, which was a sister company of the Dutch consultancy). To create the necessary financial and organizational commitment, a Dutch steering group was formed with high-level representatives of the participating organizations. In addition, a Romanian consultative committee was formed with high-level representatives of national, regional, and local authorities. The project structure is schematized in Figure 2.

Preparations for the project started in May 2008 when the Dutch project team paid a preparatory visit to the project area and discussed the project idea with various regional and local actors. On the basis of these discussions, a project proposal was developed, finances were mobilized, and the Romanian project team was formed. The ultimate project goals were to improve the water system and the living conditions of the population in the Tecucel river basin and also to develop a long-term cooperation and to exchange knowledge between Dutch and Romanian actors involved. The project was divided into four phases: (1) analyzing the existing situation and developing an action plan for the project; (2) identifying "no regret" measures, i.e., measures that would contribute to the realization of a more sustainable water system and could be implemented relatively easy; (3) creating institutional and financial support and commitment for a program of measures; and (4) preparing a master plan including no-regret measures.

International collaboration was facilitated by a series of exchange visits. Dutch actors went for six "missions" to Romania and Romanian actors went for two "visits" to the Netherlands (see Table 1 for an overview). The length of these exchanges, i.e., the actual time spent with the other actors, varied between one and five days. The Dutch missions to Romania included three visits to the project area (missions 1, 2, and 6), two visits to Galaţi (home base of regional authorities, missions 3 and 4), and one visit to Iaşi (home base of the regional water authority, mission 5). The Romanian visits to the Netherlands included a study visit by the project team and a representative of the Municipality of Galaţi (visit 1) and a visit by two representatives of the regional water company to discuss further collaboration (visit 2). In addition, the Dutch team met on a regular basis, approximately once a month, to discuss the project progress and so did the Romanian team. Outside the exchange visits, the contact between both teams went mostly via the Dutch project leader and the Romanian project secretary who had regular contact via email and phone. The interaction with high-level representatives was limited: the steering group met once in the preparation period and the consultative committee once with the Romanian team and once with both teams in the implementation period. In addition, the teams had some contact with other Romanian actors, including nongovernmental organizations and consultancy companies.

The project was implemented differently as planned. Halfway through the project, the teams concluded that the completion of the two regional master plans, by Romanian Waters and by the regional water company, made the development of another master plan redundant. Already at the project start, several members of both teams knew that other master plans were being developed. However, these actors lacked in-depth insight and knowledge of the plans and did not understand how the master plans interfered with the project goals. Toward the end of the project, the Dutch team decided to focus instead more on the identification and development of no-regret measures and on the possibilities for further collaboration. Eventually, none of the formulated no-regret measures could be implemented because of a lack of support and resources from higher level authorities. The main follow-up of the project was that the Dutch water company and water authority decided to engage in a "water partnership" with the regional Romanian water company for a period of three years.

\section{Methods}

The case study is part of a research focusing on the effectiveness of Dutch-funded projects in Romania. Within the context of this research, the first author (principal researcher) was given permission by the project teams to study the project. Data were collected from the project beginning (March 2008) to the end and beyond (July 2011). Documentation, interviews, and observations were used as main sources. The researcher analyzed a wide variety of project documents (plans, minutes, reports, letters, and emails), 
Table 1. Overview of missions by Dutch actors to Romania and (study) visits by Romanian actors to the Netherlands.

\begin{tabular}{|c|c|c|}
\hline Activity & Period & Scope, participants, and activities of various missions and visits \\
\hline Mission 1 & Oct 2009 & $\begin{array}{l}\text { Dutch team visits Tecuci to discuss the project content and organization in plenary and small-scale } \\
\text { meetings and to visit the project area; two Dutch actors visit the water company and county } \\
\text { council of Galaţi }\end{array}$ \\
\hline Visit 1 & Dec 2009 & $\begin{array}{l}\text { Romanian team visits Groningen area to further define the process in plenary meetings and } \\
\text { interactive workshops and to visit the region }\end{array}$ \\
\hline Mission 2 & Jun 2010 & $\begin{array}{l}\text { Dutch team visits Tecuci to discuss the project progress and goals with the Romanian team in } \\
\text { plenary meetings and workshops }\end{array}$ \\
\hline Mission 3 & Sep 2010 & Three Dutch actors visit a Dutch-Romanian workshop on flood risk management in Galaţi \\
\hline Mission 4 & Oct 2010 & Two Dutch actors visit the water company in Galaţi to discuss future collaboration \\
\hline Visit 2 & Nov 2010 & Water company Galaţi visits three Dutch actors to discuss future collaboration \\
\hline Mission 5 & Feb 2011 & Dutch consultant visits regional water authority to discuss future collaboration \\
\hline Mission 6 & Apr 2011 & $\begin{array}{l}\text { Dutch team visits water company in Galaţi to discuss future collaboration and Tecuci to evaluate } \\
\text { the project with the Romanian team }\end{array}$ \\
\hline
\end{tabular}

policy documents (legislation, policies, plans, and strategies), and other relevant material such as websites. During the project, informal interviews were conducted. Semistructured interviews were conducted shortly after the project was finalized (June and July 2011) with six members of the Dutch team (in Dutch) and nine Romanian actors (in English or in Romanian with translation into English). Data from direct observations were collected during four missions (1, 2, 3, and 6) and during the first visit. During the entire project, the researcher had regular contact with the project participants and other key informants.

Data collection focused on the project in general (i.e., history, physical, administrative, and policy contexts, objectives, plan, interactions, results, and follow-up actions) and the actorinteraction process. Data about the interactive process and the motivations, cognitions, resources, and relations were collected at various points in time. To develop an understanding of social learning processes, we examined changes in the characteristics of individual actors and the development of collective outcomes, which were shared or agreed upon by groups of actors. The analysis of the actor-interaction process, i.e., the collection and interpretation of data, was structured along four lines of understanding and we organized the results section of this paper accordingly. These lines of understanding and related questions are:

1. Motivations and a joint motivating goal: Why does an actor participate in the project? How does the project relate to personal or organizational objectives? Does external pressure or a lack of resources affect an actors' motivation? Does an actor expect to contribute knowledge or learn new things? Does an actor enjoy the process? When, why, and how has a motivation been changing? Are actors motivated for the same goals?

2. Cognitions and negotiated knowledge: What does an actor believe to be the central problem and project focus? What does an actor see as potential solutions? Who should be involved in the project? How does an actor value the adopted project structure and approach? How does an actor value knowledge that has been used or generated? Has an actors' view on the project content and process been changing? Do actors having similar beliefs about the project, the process, and the results?

3. Resources and pooling of resources: What does an actor contribute in terms of human resources (involvement), knowledge (information and expertise), financial resources, and institutional resources (power to influence policy or to get things done)? How does an actor value the contribution of him/herself and of other actors? What resources are attributed to other actors (inside and outside the project teams)? What resources have been mobilized or developed during the project?

4. Relations and trust: What (personal or professional) relations were existing between various actors? Does an actor have sufficient opportunities to interact with other actors? Does an actor experience any problems while interacting with other actors in the project? Does an actor trust the competence and willingness of other actors? Does an actor have the intention or the expectation to collaborate with one of the other actors in the (near) future?

The collected data were structured using software for qualitative data analysis (ATLAS.ti). More information about the case study methodology and a detailed narrative of the case can be found in a case report (Vinke-de Kruijf 2012). Draft versions of the interview reports and the case report were reviewed and, if applicable, corrected by respondents and key informants.

\section{CASE STUDY RESULTS}

\section{Motivations and a joint motivating goal}

The Dutch organizations had various reasons to participate in the project. Among the most important reasons were commitments to the realization of the Millennium Development Goal on water and sanitation, the creation of business opportunities, and improved collaboration with other actors in the North of the Netherlands. At the individual level, actors also just enjoyed participating in an interesting project and expected that they could, because of their knowledge or network, help to reduce water problems in the area. A positive self-effectiveness assessment was thus a source of motivation for some of the Dutch actors. This did not apply to all Dutch actors; some also doubted 
whether their organization could and should be involved in international water projects.

Most of the Dutch actors hoped and expected to achieve concrete results. However, their interactions with the Romanian team had a negative effect on their motivations. Romanian actors were hesitant to take initiative, which made Dutch actors doubt their motivations, and had less insights into and influence on policy processes than expected, which made Dutch actors feel misinformed. In addition, the project gave the Dutch team new insights into the regional master plans and the policy network. As a result, they became increasingly aware as a team that they could not achieve concrete outcomes. Next, we noted various learning processes that affected the individual willingness of actors to further collaborate. For example, the consultancy discovered that the potential contribution of their Romanian sister company and business opportunities in Romania were less than expected (demotivating effect). The water company was positive about its collaboration with the regional water company and therefore became motivated to develop a long-term partnership (motivating effect).

On the Romanian side, all actors had a clear interest in learning from the Dutch team. Participants from the municipality and the water company of Tecuci especially hoped that the project would form a basis for concrete improvements in their water system. The interactions motivated these organizations to intensify their collaboration. Unlike the other Romanian organizations, they also expected to benefit from the water partnership. Even though the project had no tangible benefits and took longer than expected, the collaboration was motivating for all Romanian actors. As the project provided them with new solutions, insights, and perspectives, they were very interested to further collaborate with the Dutch team. Thus, learning, at the individual and collective level, changed the motivations of actors involved. However, learning and social learning did not result in a goal that was supported by all participating actors.

\section{Cognitions and negotiated knowledge}

The project was initiated for the purpose of reducing flood risks. However, the Dutch water authority soon decided to also address drinking water and wastewater treatment problems. All participants were in favor of this integrated approach, but they had diverse opinions about what was most important, e.g., reducing flood risks, improving drinking water and wastewater treatment, or improving collaboration. For the Dutch team, the integration of various water domains was an obvious choice given the interrelations between both sectors. Moreover, it was seen as a means to bring various actors together and to create opportunities for fundraising. Romanian actors initially perceived the integrated approach as an important, innovative, and interesting aspect of the project. The project experiences changed and diversified their opinions. Some argued that the approach was of added value, because the formation of integrated teams brought various actors together. Others argued that the approach was never implemented or that it had been an obstacle in the development of plans and solutions.

The participation of actors from various governance (administrative) levels was another important aspect of the project. In consultation with local and regional actors, the Dutch team suggested forming a local team and a consultative committee on the Romanian side. The formation of the committee was successful, but most actors concluded that it did not function well. Furthermore, the plan was to apply an interactive design method that would promote the active involvement of local authorities and other stakeholders, e.g., interest groups or landowners. Actors of both project teams had no experience with the method until its small-scale test application in visit 1. From this experience, the Dutch actors learned that the method creates energy among participants. However, some also started to doubt the added value of the method when solving problems without a clear spatial component, such as drinking water supply problems. The Romanian team valued the method and some of them also used it later in dealing with a multiactor problem. The planned application of the method in Romania had to be postponed because of air traffic problems and was later abandoned entirely. The decision to abandon the method from the project was made by the Dutch team on the basis of their new insights in the method, acquired during the small-scale application, and in the Romanian policy network. The Romanian team regretted the decision. As for the overall project design, actors arrived at different conclusions. Some argued that the project was much too localoriented; others doubted whether earlier and closer involvement of national actors would have made a difference.

Through their interactions, actors involved learned about the Romanian policy network, the potential of the adopted approach, the problems in the area, especially Dutch actors, and potential solutions, especially Romanian actors. Because of these new insights, the teams jointly decided not to develop an integrated master plan and to focus on the development of a list of measures instead. The list of measures was agreed upon, but both teams had diverse opinions on what should be done next. Although the Romanian team suggested developing an integrated action plan for seven measures, the Dutch team decided, in consultation with two regional Romanian actors (not part of the project team), to focus on the further development of two. Thus, actors collectively learned and developed a list of measures. However, they did not develop a shared understanding of how to deal with or prioritize problems.

\section{Resources and pooling of resources}

Financial resources for the project were provided partly by the bank of the Dutch water authorities and partly by the Dutch organizations involved. To mobilize necessary institutional and financial support for follow-up actions, a Romanian consultative committee was established. The meetings of this committee were attended by regional and local authorities but, despite the efforts made by the Romanian team, not by national authorities. Toward the end of the project, the Dutch team directly contacted regional and national authorities to mobilize support, but also without success. The teams eventually concluded that to mobilize regional or national support for local measures was not feasible because the measures did not have priority in existing master plans.

Human resources and knowledge were contributed by both project teams. The Dutch organizations were represented by one or several actors who had complementary expertise and participated in just a few of nearly all missions. The relatively large number of Dutch organizations involved enabled the pooling of resources but probably also made it more difficult to keep each other informed and to reach an agreement. A factor 
that complicated the collaboration was that the project leader, who was the only Dutch actor with experience in in Romania (though not in water projects), could not attend the first mission. Furthermore, the division of tasks among Dutch actors raised discussion. Funds only covered the involvement of the project leader organization, which implied that this organization was expected to take on most of the actual work, e.g., writing of the project proposal, leading and managing the project, preparing and chairing meetings, and writing minutes. However, the organizational and financial support was too limited to execute all these tasks in a satisfactory manner. Thus, the collaboration and pooling of resources in the Dutch team was far from optimal.

Generally, the Dutch team concluded that their actual contribution was more related to the process, e.g., energizing and connecting people, than to the content. They were disappointed about the actual use and impact of their resources, but highlighted that the project had been a great learning experience that increased their capacity to implement national and international projects. Two Dutch organizations decided to pool their resources with the regional Romanian water company in a water partnership. This outcome was a direct result of their interactions in the periphery of the project.

The Romanian team was expected to contribute knowledge about existing problems and the policy network. All members were actively involved and contributed information about the problems and plans that were relevant to their own organization. The technical assistant and project secretary collected, translated, and communicated this information to the Dutch team. This was not very effective, since the Dutch team had difficulties understanding and valuing the provided information. Working groups with members of both teams were further established to enhance the creation of a knowledge base but people in these groups never started to really interact with each other. One of the bottlenecks was that the local team appeared to have little insight in the meaning of ongoing policy developments for the project and project area. Relevant information on this aspect became available rather late and was mostly provided by external Romanian consultants. When more information became available, the project focus shifted to the creation of support for measures that had local priority but were not included in existing master plans.

The above shows that the pooling of Dutch and Romanian resources was not without problems and that actors were unable to mobilize the resources that were needed to solve any of the local problems in the project area. However, the project did result in an increase of knowledge, insights, and skills and led to the pooling of resources for a partnership that involved some of the participating organizations.

\section{Relations and trust}

Before the project started, most Dutch actors were familiar with the other organizations but had no direct relational experiences with the other actors. In fact, one of the informal project objectives was to develop mutual relations. Although some members of the team did not get along very well, most of the actors developed good personal relations and trust in the others, which potentially could enhance and ease future collaboration.

Most of the members of the local Romanian team also did not collaborate before but were familiar with each other. Although it was not natural for them to collaborate, they all had very positive relational experiences and emphasized the involvement, commitment, and enthusiasm of other actors. Nonlocal actors were generally not familiar with each other and also not with the local actors. One of the project outcomes was therefore that new relations between and across various governance levels were established. This could ease future problem solving. Thus, the project contributed to the development of relational qualities that are supportive of future collaboration in the Netherlands and in Romania.

Most actors involved had very little experience with international water projects. During the project, there was limited direct and personal interaction between most members of the project teams. Language barriers played a role: the members of the Romanian team had limited knowledge of English, which meant that there was usually a need for translation, limiting the direct interaction between actors of both teams. Outside of international visits, informal and formal communication mostly went via the project leader and the project secretary. The collaboration between them was very good.

With regard to the overall collaboration, the Romanian team valued their collaboration with and the commitment and expertise of the Dutch team and was interested in future collaboration. As explained before, the Dutch team expected their counterparts to be more proactive and had the impression that information was withheld. As a result of these negative experiences, they developed less trust in their counterparts and became less willing to collaborate. What also played a role was that the Dutch team learned about the policy network and realized that it would be more productive to collaborate with regional actors who speak English and have more power to get things done.

\section{DISCUSSION: LEARNING AS A BASIS FOR FURTHER COLLABORATION?}

To understand the nature of effects of social learning, we examined a collaborative process through which various Dutch and Romanian organizations aimed to solve, or at least reduce, water problems. The actors who represented these organizations had diverse motivations, cognitions, and resources and were not used to collaborating with each other.

The case study results show that actors developed new insights and knowledge, implying that learning took place. Dutch actors developed a better understanding of existing problems and learned how to approach and implement projects in an international setting (substantive learning). They also learned about the perspectives and capacity of other actors and some of them developed relations that could support further collaboration with some of the other Dutch actors (relational learning). Romanian actors learned about potential solutions and how to deal with multiactor problems (substantive learning). They also learned about their own position in the policy network, perspectives of other Romanian actors, and developed relations that could support further collaboration among their fellow Romanian and with Dutch actors (relational learning). Many of these learning processes can be referred to as social learning. They would not have occurred without the interactions that took place within the context of the project and they led to shared insights and understandings concerning various aspects of the project. Thus, learning went on several occasions beyond changes at the individual level. 
When comparing the learning processes of both project teams, we observed that they went through different learning processes. The case confirms that external and local actors who participate in the same process tend to learn about different aspects and topics (Rist et al. 2006). In addition, the case shows that the effect of learning differs per actor. The external experts, i.e., the Dutch actors, had diverse opinions about the process course and outcomes, but jointly concluded that the adopted approach had not been successful and that their collaboration with the local team, and sometimes also with each other, had been difficult. Although they initially had the intention to develop a long-term collaboration with their local Romanian counterparts, they eventually decided to withdraw from further collaboration. The Romanian team wanted to continue the collaboration, which did not happen because the learning by the Dutch actors was decisive. Naturally, this outcome is not set in stone: further collaboration is unlikely, but should not be ruled out. For example, local Romanian actors may be successful in mobilizing resources for another project and decide to approach Dutch actors again. If such a new project was organized differently, Dutch actors may decide to participate despite their experiences in this project (Rousseau et al. 1998).

The difference between the learning processes of both teams is striking. A possible explanation for the negative experiences of the Dutch team could be the newness of the collaboration. Research focusing on trust shows that in relatively new relations, actors have little faith in each other implying that unmet expectations easily lead to termination (Rousseau et al. 1998). However, this does not explain why the Romanian team, for whom the collaboration was also new and less effective than hoped for, was still interested in further collaboration. Why was the interactive process not as disappointing for the Romanian team as for the Dutch team? This is likely to be rooted in their diverse self-effectiveness assessments, one of the sources of motivation. When an actor perceives that preferred performance is beyond its capacity, a demotivating effect can occur (De Boer and Bressers 2011). Most members of the Dutch team initially had a positive self-effectiveness assessment; they believed that they could contribute to the improvement of water management in Romania. However, they learned that this goal was beyond the resources of both teams. Because the Romanian team was more expectant and looking for ways to increase their skills, the process did not have such a demotivating effect on them.

Although social learning took place in the case study, actors did not create a common basis on which collaborative follow-up actions can be based. The case actually demonstrates that social learning can positively and also negatively influence further collaboration. The negative influence of social learning on further collaboration is seldom emphasized in the scholarly literature. Among the few exceptions are two recent studies focusing on pilot projects (Vreugdenhil 2010, Van Mierlo 2012) and participatory methods (Scholz et al. 2013). These scholars argue that learning can be convergent (or constructive) and divergent (or destructive). Convergent learning involves the developments of shared understandings (Scholz et al. 2013), the alignment of experiences and actions (Van Mierlo 2012), and convergences in actor networks and ways of thinking (Vreugdenhil 2010). In contrast, learning can have the opposite effect, drifting actors further apart and complicating future collaboration (Vreugdenhil 2010). In other words, interactions may produce or confirm negative perceptions of other actors, deepen differences in views, or worsen relationships (Schusler et al. 2003, Muro and Jeffrey 2008). When this is the case, we chose to call this an unconstructive learning process.

The case study illustrates that a single project may involve multiple and diverse learning processes. The case project itself is the result of a constructive learning process: both teams developed a joint basis and started pooling resources to implement the project. Also both teams had constructive interactions with members of their own team. As for the interactions between Dutch and Romanian actors, they were constructive from a Romanian perspective and predominantly unconstructive from a Dutch perspective. An exception is the interactions that took place between Dutch actors and a regional Romanian water company in the periphery of the project. As a result of these constructive interactions, a partnership was formed between two Dutch actors and one regional Romanian actor.

In this paper, we used the part of the Contextual Interaction Theory that focuses on the interactive process to study processes of social learning. A more elaborate version of the theory incorporates the relation between this interactive process and contextual factors. It states that the wider, structural (governance) and specific contexts of an actor-interaction process influence the process via the characteristics of actors involved. Learning processes in international projects, such as this case study, are obviously affected by the country contexts of the actors involved. A factor that was of particular importance in the analyzed case was the misfit between the centralized governance context and the integrated and bottom-up approach of the project (Vinke-de Kruijf et al. 2013b). It is within this context that the learning of Dutch actors was decisive: they possessed, in contrast to their local Romanian counterparts, the resources to continue the collaboration and could therefore also decide to discontinue their collaboration. If other, more resourceful Romanian actors would have been involved, the process may have developed differently. That such actors were not involved partly relates to the lack of knowledge and insights of the actors involved in the governance context and also to the lack of priority that higher level authorities give to local problems. Thus, the case demonstrates that learning influences further collaboration not only through what actors learn, but also through who learns and how resources are distributed among actors. To understand the actual impact of learning, one therefore also needs to have an insight in the governance context in which learning occurs.

\section{CONCLUSION}

In this paper, we analyzed the nature and effects of social learning and how this may establish a basis for further collaboration. Insights from social learning and policy implementation literature were integrated into a conceptual model. The model asserts that collaborative settings enhance substantive learning and relational learning, which changes the motivations, cognitions, and resources of actors involved. Social learning means that changes go beyond the individual level and lead to collective outcomes. We identified four types of collective outcomes: a motivating goal, negotiated knowledge, pooling of resources, and trust (associated 
with positive relational experiences). These outcomes can form a basis for further collaboration, which are often needed to actually reduce an environmental problem.

We applied the presented theoretical concepts to an international water project that was implemented in collaboration between Dutch and Romanian actors. In the case study, Dutch actors and Romanian actors went through different learning processes leading to different impacts. Although most literature emphasizes the constructive nature of social learning, i.e., social learning enables further collaboration or collective action), the case study demonstrates that social learning can also be, partly, unconstructive. In the case study, the unconstructive learning of the external and more resourceful actors had most impact. Their relational experiences were negative and their interactions had a demotivating effect as they learned that their intended actions were beyond the capacity of the actors involved. Hence, they decided to withdraw from further collaboration. Because local actors lack the resources to initiate further collaboration, no collaborative actions are planned to solve the water problems in the project region.

We conclude that interactions can facilitate learning and the development of collective outcomes. The collective outcomes of social learning can form a pathway for further collaboration but can also have the opposite effect. A single project can involve different individual and collective learning processes. Each of these social learning processes may have another effect. What actors learn and the effect of their learning processes depends, among others, on the role and country backgrounds of the actors involved. The context of the case was not focused upon in this paper, but the case study results show that the impact of learning processes cannot be separated from the context, and particularly the governance context, in which they occur. To understand the effects of learning in collaborative settings, it is crucial to understand not only how much actors learn through their multiple and diverse interactions, but also what is learned and whose learning has most impact.

Responses to this article can be read online at: http://www.ecologyandsociety.org/issues/responses. php/6540

\begin{abstract}
Acknowledgments:
The authors thank the participants of the project that was used as a case study, in particular the members of the Dutch and Romanian project teams, for their collaboration. We further thank the anonymous reviewers and Gül Özerol of the University of Twente for their helpful comments on previous versions of the paper. The publication of this article was supported by a Marie Curie IntraEuropean Fellowship grant within the European Community Framework Programme (PIEF-GA-2012-326268).
\end{abstract}

\section{LITERATURE CITED}

Bandura, A. 1986. Social foundations of thought and action: a social cognitive theory. Prentice Hall, Englewoods Cliffs, New Jersey, USA
Bierly, P. E. III, E. H. Kessler, and E. W. Christensen. 2000. Organizational learning, knowledge and wisdom. Journal of Organizational Change Management 13(6):595-618. http://dx.doi. org/10.1108/09534810010378605

Bressers, H. T. A. 2009. From public administration to policy networks: contextual interaction analysis. Pages 123-142 in $\mathrm{S}$. Nahrath and F. Varone, editors. Rediscovering public law and public administration in comparative policy analysis: tribute to Peter Knoepfel. Presses Polytechniques et Universitaires Romandes, Lausanne, Switzerland.

Cundill, G., and R. Rodela. 2012. A review of assertions about the processes and outcomes of social learning in natural resource management. Journal of Environmental Management 113:7-14. http://dx.doi.org/10.1016/j.jenvman.2012.08.021

De Boer, C., and H. T. A. Bressers. 2011. Complex and dynamic implementation processes: the renaturalization of the Dutch Regge River. University of Twente in collaboration with the Dutch Water Governance Centre, Enschede, the Netherlands. [online] URL: http://purl.utwente.n1/publications/77862

De Laat, M. F., and P. R. J. Simons. 2002. Collective learning: theoretical perspectives and ways to support networked learning. European Journal for Vocational Training 27(3):13-24.

Gerlak, A. K., and T. Heikkila. 2011. Building a theory of learning in collaboratives: evidence from the Everglades Restoration Program. Journal of Public Administration Research and Theory 21(4):619-644. http://dx.doi.org/10.1093/jopart/ $\underline{\text { muq089 }}$

Hommes, S., J. Vinke-de Kruijf, H. S. Otter, and G. Bouma. 2009. Knowledge and perceptions in participatory policy processes: lessons from the Delta-region in the Netherlands. Water Resources Management 23(8):1641-1663. http://dx.doi.org/10.1007/ s11269-008-9345-6

Huitema, D., C. Cornelisse, and B. Ottow. 2010. Is the jury still out? Toward greater insight in policy learning in participatory decision processes - the case of Dutch citizens' juries on water management in the Rhine Basin. Ecology and Society 15(1): 16. [online] URL: http://www.ecologyandsociety.org/vol15/iss1/ $\underline{\operatorname{art} 16 /}$

Ison, R., N. Röling, and D. Watson. 2007. Challenges to science and society in the sustainable management and use of water: investigating the role of social learning. Environmental Science and Policy 10(6):499-511. http://dx.doi.org/10.1016/j.envsci.2007.02.008

Koontz, T. M., and C. W. Thomas. 2006. What do we know and need to know about the environmental outcomes of collaborative management? Public Administration Review 66:111-121. http:// dx.doi.org/10.1111/j.1540-6210.2006.00671.x

Koppenjan, J. F. M., and E. Klijn. 2004. Managing uncertainties in networks: a network approach to problem solving and decision making. Routledge, London, UK.

Leeuwis, C., and A. Van den Ban. 2004. Communication for rural innovation: rethinking agricultural extension. Blackwell Science, Oxford, UK. http://dx.doi.org/10.1002/9780470995235

Mandarano, L. 2008. Evaluating collaborative environmental planning outputs and outcomes: restoring and protecting habitat 
and the New York-New Jersey harbor estuary program. Journal of Planning Education and Research 27(4):456-468. http://dx.doi. org/10.1177/0739456X08315888

Muro, M., and P. Jeffrey. 2008. A critical review of the theory and application of social learning in participatory natural resource management processes. Journal of Environmental Planning and Management 51(3):325-344. http://dx.doi.org/10.1080/09640560801977190

Newig, J., D. Günther, and C. Pahl-Wostl. 2010. Synapses in the network: learning in governance networks in the context of environmental management. Ecology and Society 15(4): 24. [online] URL: http://www.ecologyandsociety.org/vol15/iss4/ $\underline{\operatorname{art} 24 /}$

Owens, K. A. 2008. Understanding how actors influence policy implementation: a comparative study of wetland restorations in New Jersey, Oregon, The Netherlands and Finland. Dissertation. University of Twente, Enschede, The Netherlands. http://dx.doi. org/10.3990/1.9789036526982

Pahl-Wostl, C., M. Craps, A. Dewulf, E. Mostert, D. Tabara, and T. Taillieu. 2007. Social learning and water resources management. Ecology and Society 12(2): 5. [online] URL: http:// www.ecologyandsociety.org/vol12/iss2/art5/

Reed, M. S., A. C. Evely, G. Cundill, I. Fazey, J. Glass, A. Laing, J. Newig, B. Parrish, C. Prell, C. Raymond, and L. C. Stringer. 2010. What is social learning? Ecology and Society 15(4): r1. [online] URL: http://www.ecologyandsociety.org/vol15/iss4/ $\underline{\text { resp1/ }}$

Rist, S., M. Chiddambaranathan, C. Escobar, and U. Wiesmann. 2006. "It was hard to come to mutual understanding..."- - the multidimensionality of social learning processes concerned with sustainable natural resource use in India, Africa and Latin America. Systemic Practice and Action Research 19(3):219-237. http://dx.doi.org/10.1007/s11213-006-9014-8

Rousseau, D. M., S. B. Sitkin, R. S. Burt, and C. Camerer. 1998. Not so different after all: a cross-discipline view of trust. Academy of Management Review 23(3):393-404. http://dx.doi.org/10.5465/ AMR.1998.926617

Scholz, G., A. Dewulf, and C. Pahl-Wostl. 2013. An analytical framework of social learning facilitated by participatory methods. Systemic Practice and Action Research. http://dx.doi.org/10.1007/ $\underline{\mathrm{s} 11213-013-9310-\mathrm{Z}}$

Schusler, T. M., D. J. Decker, and M. J. Pfeffer. 2003. Social learning for collaborative natural resource management. Society \& Natural Resources 16(4):309-326. http://dx.doi. org/10.1080/08941920309158

Stenmark, D. 2002. Information vs. knowledge: the role of intranets in knowledge management. Pages 928-937 in System sciences. HICSS. Proceedings of the 35th Hawaii International Conference on System Sciences. IEEE, 7-10 January 2002, Hawaii. [online] URL: http://ieeexplore.ieee.org/stamp/stamp.jsp?tp= $\underline{\text { \&arnumber }=994043}$
Steyaert, P., and J. Jiggins. 2007. Governance of complex environmental situations through social learning: a synthesis of SLIM's lessons for research, policy and practice. Environmental Science and Policy 10(6):575-586. http://dx.doi.org/10.1016/j. envsci.2007.01.011

Tàbara, J. D., and C. Pahl-Wostl. 2007. Sustainability learning in natural resource use and management. Ecology and Society 12(2): 3. [online] URL: http://www.ecologyandsociety.org/vol12/iss $2 /$ $\underline{\operatorname{art} 3 /}$

Van Mierlo, B. 2012. Convergent and divergent learning in photovoltaic pilot projects and subsequent niche development. Sustainability: Science, Practice, \& Policy 8(2):4-18. [online] URL: http://sspp.proquest.com/archives/vol8iss2/0901-002.vanmierlo. $\underline{\mathrm{html}}$

Vinke-de Kruijf, J. 2011. The role of Dutch expertise in Romanian water projects: case study 'Room for the River in Cat's Bend, Romania.' CE\&M research report 2011R-001/WEM-001, University of Twente, Enschede, the Netherlands. [online] URL: http://doc.utwente.n1/77883

Vinke-de Kruijf, J. 2012. The role of Dutch expertise in Romanian water projects: case study "Integrated Water Management in the Tecucel River Basin.” CE\&M research report 2012R-001/ WEM-001, University of Twente, Enschede, the Netherlands. [online] URL: http://doc.utwente.n1/80901/

Vinke-de Kruijf, J., D. C. M. Augustijn, and H. T. A. Bressers. 2012. Evaluation of policy transfer interventions: lessons from a Dutch-Romanian planning project. Journal of Environmental Policy and Planning 14(2):139-160. http://dx.doi. org/10.1080/1523908X.2012.680700

Vinke-de Kruijf, J., S. M. M. Kuks, and D. C. M. Augustijn. $2013 a$. Connective capacity in a dynamic context: changing water governance structures in Romania. Pages 49-67 in J. Edelenbos, N. Bressers, and P. Scholten, editors. Water governance as connective capacity. Ashgate, London, UK.

Vinke-de Kruijf, J., C. Teodosiu, H. T. A. Bressers, and D. C. M. Augustijn. 2013b. How contextual factors influence the effectiveness of international projects: the case of Dutch-funded flood risk management projects in Romania. Pages 57-75 in C. De Boer, J. Vinke-de Kruijf, G. Ozerol, and H. Bressers, editors. Water governance, policy and knowledge transfer: international studies on contextual water management. Earthscan from Routledge, London, UK.

Vreugdenhil, H. S. I. 2010. Pilot projects in water management: practicing change and changing practice. Dissertation. Delft University of Technology, Delft, the Netherlands. [online] URL: http://repository.tudelft.nl/view/ir/uuid\%3A91bda74bcf5d-4caf-8159-1e57650291ccl

Zaharia, L., S. Catang, E. Crgciun, and G. Toroimac. 2008. Flood vulnerability of Tecuci city: the role of natural and socioeconomic factors. Revista Riscuri si catastrofe VII(5):130-140. 